\title{
Model Kesuksesan Sistem Informasi Delone Dan Mclean Terhadap Sistem Informasi Akademik Pada Universitas Bina Insani
}

\author{
Sahara Ramadhan ${ }^{1,{ }^{\star}}$, Nadya Safitri ${ }^{2}$, Sigit Setiawan $^{1}$ \\ ${ }^{1}$ Sistem Informasi; Universitas Bina Insani; Jl. Siliwangi No. 6 Rawa Panjang Bekasi Timur Kota \\ Bekasi 17114 Indonesia, Telp. (021) 82436886 / (021) 82436996. Fax. (021) 82400924; e-mail: \\ sahararamadhan@binainsani.ac.id, sigit@binainsani.ac.id \\ ${ }^{2}$ Rekayasa Perangkat Lunak; Universitas Bina Insani; Jl. Siliwangi No. 6 Rawa Panjang Bekasi \\ Timur Kota Bekasi 17114 Indonesia, Telp. (021) 82436886 / (021) 82436996. Fax. (021) \\ 82400924; e-mail: nadyasafitri@binainsani.ac.id \\ * Korespondensi: e-mail: nadyasafitri@binainsani.ac.id
}

Diterima: 29 Juni 2021; Review: 30 Juni 2021; Disetujui: 02 Juli 2021

Cara sitasi: Ramadhan S., Safitri N. 2020. Model Kesuksesan Sistem Informasi Delone dan Mclean Terhadap Sistem Informasi Akademik di Universitas Bina Insani. Information Management for Educators and Professionals Vol. 5 (2): halaman 85-96.

\begin{abstract}
Abstrak: Sistem Informasi Akademik membantu kegiatan pengelolaan atau pengadministrasian berbagai kegiatan dalam rangka terselenggaranya proses belajar mengajar yang efektif dan efisien di suatu Lembaga Pendidikan tinggi. Universitas Bina Insani telah menerapkan Sistem Informasi Akademik selama lebih dari dua tahun. Namun pada kenyataanya sistem tersebut memiliki beberapa masalah terhadap pengunaannya. Agar suatu sistem informasi dapat berjalan dengan optimal sesuai dengan keperluan penggunanya, maka perlu adanya evaluasi terhadap sistem informasi. Evaluasi ini menggunakan metode DeLone \& McLean (2003) dengan 4 variabel yaitu kualitas sistem, kualitas informasi, kualitas layanan dan kepuasan pengguna. Populasi pada penelitian ini adalah Mahasiswa dan dosen fakultas informatika serta bagian akademik dan bagian Pendidikan dengan jumlah sampel yang digunakan sebanyak 92 responden. Instrumen penelitian menggunakan kuesioner online. Adapun metode analisis yang digunakan Partial Least Square (PLS) dengan menggunakan software SmartPLS.

Hasil analisis ini adalah diterimanya tiga dari tiga hipotesis yang diuji. Sehingga hasil tersebut menunjukan kualitas sistem mempunyai pengaruh yang positif dan signifikan terhadap kepuasan pengguna dengan nilai koefisiensi jalur sebesar 0,407 dan $t$-statistic sebesar 4,699, kualitas informasi mempunyai pengaruh yang positif dan signifikan terhadap kepuasan pengguna dengan nilai koefisiensi jalur sebesar 0,336 dan $t$-statistic sebesar 2,782 sedangkan kualitas layanan berpengaruh positif tetapi tidak signifikan terhadap kepuasan pengguna dengan nilai koefisiensi jalur sebesar 0,206 dan t-statistic sebesar 1,898. Dengan demikian, Penelitian ini menunjukan bahwa Sistem Informasi Akademik yang telah diterapkan di Universitas Bina Insani dapat dikatakan sukses dalam memberikan manfaat yang baik terhadap penggunanya.
\end{abstract}

Kata kunci: Sistem Informasi Akademik, DeLone \& McLean, SmartPLS, PLS

Abstract: The Academic Information System assists activities in the management or administration of various activities in the context of implementing an effective and efficient teaching and learning process in a higher education institution. Bina Insani University has implemented an Academic Information System for more than two years. However, in fact the system has several problems with its use. In order for an information system to run optimally according to the needs of its users, it is necessary to evaluate the information system. This evaluation uses the DeLone \& McLean (2003) method with 4 variables, system quality, information quality, service quality and user satisfaction. The population in this study were students and lecturers of the faculty of informatics as well as the academic and education 
sections with a total sample size of 92 respondents. The research instrument used an online questionnaire. The analysis method used is Partial Least Square (PLS) using the SmartPLS software. The result of this analysis is the acceptance of three of the three hypotheses tested. So that these results indicate the quality of the system has a positive and significant effect on user satisfaction with a path coefficient value of 0.407 and a $t$-statistic of 4.699 , information quality has a positive and significant impact on user satisfaction with a path coefficient value of 0.336 and a t-statistic of 2,782 while service quality has a positive but insignificant effect on user satisfaction with a path coefficient value of 0.206 and a t-statistic of 1.898 .

Thus, this study shows that the Academic Information System that has been implemented at Bina Insani University can be said to be successful in providing good benefits to its users.

\section{Keywords: Academic Information Systems, DeLone \& McLean, SmartPLS, PLS}

\section{Pendahuluan}

Universitas Bina Insani memiliki suatu sistem yang dapat menunjang berbagai kegiatan kampus yaitu Ecampus. Ecampus merupakan aplikasi lengkap (Enterprise) dan terpadu atau terintegrasi berbasis web yang membantu pengelolaan atau pengadministrasian berbagai kegiatan dalam rangka teselenggaranya prosess belajar mengajar yang efekti dan efisien. Ecampus inii terdiri dari beberapa modul terkait yaitu modul akademik, seleksi penerimaan mahasiswa baru, kepegawaian, keuangan, perpusatakaan dan lain-lain.

Pada penelitian ini memfokuskan pada modul akademik yaitu Sistem Informasi Akademik yang digunakan Universitas Bina Insani yang sudah diterapkan selama kurang lebih 2 tahun. Pada umumnya, sebuah sistem informasi dibuat untuk dapat mempermudah suatu proses kerja dalam bidang apapun, walaupun demikian suatu sistem informasi tentunya tidak luput dari kekurangan dan sering terjadinya masalah atau kendala selama penggunaannya. Adapun pengguna dari Sistem ini yaitu Mahasiswa, Dosen, Bagian Akademik dan Bagian Keuangan).

Selama penggunaanya ditemui beberapa masalah yaitu dibagi menjadi 4 aspek yaitu: 1). Kualitas Sistem, sistem terkadang mengalami error atau down yang mengakibatkan pengguna tidak bisa mengakses dalam beberapa waktu dan fitur-fitur dalam sistem tidak semua berjalan sesuai dengan fungsinya, 2). Kualitas Informasi, pengguna sulit dalam memahami informasi yang ada karena tampilan sistem yang terlalu monoton, 3). Kualitas Layanan, pengguna sulit untuk menghubungi bagian terkait jika terjadi error, 4). Kepuasan Pengguna, pengguna sistem belum merasa puas akan tampilan yang disajikan. Oleh karena itu perlu dilakukannya analisis terhadap kesuksesan penerapan Sistem Informasi Akademik.

Suksesnya Sistem Informasi Akademik ini, dapat diukur menggunakan model kesuksesan sistem informasi yang dikembangkan oleh Delone dan Mclean. Model ini digunakan untuk mengukur tingkat kesuksesan suatu sistem informasi dengan enam pengukuran yaitu: Kualitas Sistem (System Quality), Kualitas Informasi (Information Quality), Kualitas Layanan (Service Quality), Penggunaan (Use), Kepuasan Pengguna (User Satisfaction), Manfaat Bersih (Net Benefits). Namun, pada penelitian ini peneliti hanya menggunakan 4 pengukuran yaitu: Kualitas Sistem (System Quality), Kualitas Informasi (Information Quality), Kualitas Layanan (Service Quality) dan Kepuasan Pengguna (User Satisfaction).

Jurmadi et.al melakukan penelitian tentang kesuksesan implementasi sistem informasi skripsi. Penelitian tersebut menggunakan modifikasi model penelitian kesuksesan sistem informasi Delone dan Mclean. Terdapat lima variabel dalam penelitian ini yaitu, Kualitas Informasi, Kualitas Sistem, Kualitas Layanan, Kepuasan Pengguna dan Net Benefit. Hasil penelitian menyimpulkan Kepuasan Pengguna dipengaruhi oleh Kualitas Informasi dan Kualitas Sistem. Net Benefit dipengaruhi oleh Kepuasan Pengguna sedangkan Kualitas Layanan tidak mempunyai pengaruh terhadap Kepuasan Pengguna [1].

Berdasarkan latar belakang masalah diatas maka penelitian ini dapat dirumuskan sebagai berikut: 1). Apakah Kualitas Sistem (System Quality) Sistem Informasi Akademik berpengaruh positif terhadap Kepuasan Pengguna (User Satisfaction) Sistem Informasi Akademik? 2). Apakah Kualitas Informasi (Information Quality) Sistem Informasi Akademik berpengaruh positif terhadap Kepuasan Pengguna (User Satisfaction) Sistem Informasi Akademik? 3). Apakah Kualitas Layanan (Service Quality) Sistem Informasi Akademik berpengaruh positif terhadap Kepuasan Pengguna (User Satisfaction) Sistem Informasi Akademik? 


\section{INFORMATION MANAGEMENT FOR EDUCATORS AND PROFESSIONALS}

Vol. 5, No. 2, Juni 2021, 85 - 96

Adapun yang menjadi tujuan dalam penelitian ini yaitu: 1). Untuk mengetahui pengaruh Kualitas Sistem (System Quality) Sistem Informasi Akademik terhadap Kepuasan Pengguna (User Satisfaction) Sistem Informasi Akademik, 2). Untuk mengetahui pengaruh Kualitas Informasi (Information Quality) Sistem Informasi Akademik terhadap Kepuasan Pengguna (User Satisfaction) Sistem Informasi Akademik, 3). Untuk mengetahui pengaruh Kualitas Layanan (Service Quality) Sistem Informasi Akademik terhadap Kepuasan Pengguna (User Satisfaction) Sistem Informasi Akademik.

Adapun manfaat yang didapat dalam penelitian ini yaitu: 1). Memberikan masukan kepada peneliti selanjutnya untuk dapat digunakan sebagai bahan acuan penelitian selanjutnya. 2). Memberikan informasi mengenai kesuksesan penerapan Sistem Informasi Akademik pada Universitas Bina Insani. 3). Memberikan manfaat bagi instansi untuk lebih meningkatkan kepuasan pengguna pada Sistem Informasi Akademik. 4). Sebagai bahan masukan kepada pihak pengembang Sistem Informasi Akademik Universitas Bina Insani, agar aplikasi yang digunakan selalu memenuhi harapan penggunanya.

\section{Metode Penelitian}

Pada metode penelitian adapun yang akan dibahas yaitu teknik pengumpulan data, model kesuksesan Sistem Informasi Delone dan Mclean, Metode Partial Least Square, Metode Kuesioner dan Kerangka Pemikiran yang diterapkan dalam penelitian ini.

\section{Teknik Pengumpulan Data}

Data yang digunakan dalam penelitian ini adalah data primer dan data sekunder. Data primer adalah data yang belum pernah diolah oleh pihak tertentu untuk kepentingan tertentu. Data sekunder adalah data yang telah diolah, disimpan, disajikan dalam format atau bentuk tertentu oleh pihak tertentu untuk kepentingan tertentu [2].

Adapun teknik pengumpullan data dalam penelitian ini yaitu: 1). Observasi yaitu dengan melakukan pengamatan dan percobaan langsung terhadap sistem informasi akademik. 2). Wawancara yaitu melakukan tanya jawab terkait sistem kepada pengguna dan bagian sistem informasi Universitas Bina Insani. 3). Studi Pustaka yaitu melakukan pengumpulan data dan informasi berdasarkan sumber terkait seperti buku dan jurnal penelitian. 4). Kuesioner yaitu menyebarkan kuesioner yang didalamnya terdapat 23 pertanyaan yang diberikan kepada responden. Kuesioner ini berbentuk kuesioner online.

\section{Model Kesuksesan Sistem Informasi Delone dan Mclean}

Penelitian ini menggunakan model kesuksesan Sistem Informasi Delone dan Mclean menggunakan 4 pengukuran yaitu: Kualitas Sistem (System Quality), Kualitas Informasi (Information Quality), Kualitas Layanan (Service Quality) dan Kepuasan Pengguna (User Satisfaction).

Kualitas Sistem merupakan kualitas dari kombinasi hardware dan software dalam sistem informasi. Fokusnya adalah performa dari sistem itu sendiri, yang merujuk pada seberapa baik kemampuan perangkat keras, perangkat lunak, kebijakan, prosedur dari sistem informasi dapat menyediakan informasi kebutuhan pengguna. Indikator yang digunakan DeLone dan McLean adalah kemudahan untuk digunakan (ease of use), kemudahan untuk diakses (system flexibility), kecepatan akses (response time), dan ketahanan dari kerusakan (reliability). Selain itu juga digunakan indikator lain yaitu keamanan sistem (security) [3].

Kualitas Informasi pada penelitian Pit dan Watson dalam DeLone dan McLean (2003) merujuk pada output dari sistem informasi, menyangkut nilai, manfaat, relevansi, dan urgensi dari informasi. Sementara, variabel dalam DeLone dan McLean (2003) menggambarkan kualitas informasi yang dipersepsikan oleh pengguna, yang diukur dengan empat indikator penelitian Bailey dan Pearson yaitu keakuratan informasi (accuracy), ketepatwaktuan (timeliness), kelengkapan informasi (completeness) dan penyajian informasi (format) [3].

Kualitas pelayanan yang diterima pengguna sistem dari departemen sistem informasi dan dukungan personil IT. Sementara, variabel dalam DeLone dan McLean (2003) menggambarkan kualitas pelayanan yang dipersepsikan oleh pengguna, yang diukur dengan lima indikator yang diadaptasi dari bidang pemasaran yang dikemukan oleh Parasuraman, Zeithaml,dan Berry 
(1990:23) meliputi SERVQUAL (Service Quality), yaitu: (1) reability, (2) responsive, (3) assurance, (4) empaty, (5) tangibles [3].

Kepuasan Pengguna terhadap suatu sistem informasi adalah bagaimana cara pemakai memandang sistem informasi secara nyata, tapi tidak pada kualitas sistem secara teknik [4]. Kepuasan Pengguna berkaitan dengan respon penerima terhadap penggunaan output sistem informasi [4].

Agar mempermudah dalam memahami pengukuran yang digunakan dalam penelitian ini, semua variabel dan indikator akan disajikan pada Tabel.1:

Tabel 1. Variabel Penelitian

\begin{tabular}{|c|c|c|c|c|}
\hline Variabel & Indikator & Kode & Penjelasan & Sumber \\
\hline \multicolumn{5}{|c|}{ Variabel Independen } \\
\hline \multirow[t]{6}{*}{$\begin{array}{l}\text { Kualitas } \\
\text { Sistem (X1) }\end{array}$} & Keandalan sistem & $\mathrm{X} 1.1$ & $\begin{array}{l}\text { Sistem Informasi Akademik tahan dari berbagai } \\
\text { macam kerusakan serta kesalahan yang dapat } \\
\text { terjadi kapanpun. }\end{array}$ & \multirow[t]{4}{*}{$\begin{array}{l}\text { Belardo, } \\
\text { Karwan, dan } \\
\text { Wallace (1982) }\end{array}$} \\
\hline & $\begin{array}{l}\text { Kemudahan } \\
\text { penggunaan }\end{array}$ & $\mathrm{X} 1.2$ & $\begin{array}{l}\text { Sistem Informasi Akademik mudah digunakan } \\
\text { oleh pengguna. }\end{array}$ & \\
\hline & Kemudahan dipelajari & $\mathrm{X} 1.3$ & $\begin{array}{l}\text { Sistem Informasi Akademik mudah dipelajari } \\
\text { oleh pengguna. }\end{array}$ & \\
\hline & Waktu Respon & $\mathrm{X} 1.4$ & $\begin{array}{l}\text { Sistem Informasi Akademik mampu merespon } \\
\text { dengan cepat permintaan informasi yang } \\
\text { dibutuhkan pengguna. }\end{array}$ & \\
\hline & $\begin{array}{l}\text { Kegunaan fitur-fitur } \\
\text { dan fungsi-fungsi } \\
\text { sistem. }\end{array}$ & $\mathrm{X} 1.5$ & $\begin{array}{l}\text { Sistem Informasi Akademik memiliki fitur-fitur } \\
\text { yang dapat berjalan sesuai dengan fungsinya. }\end{array}$ & $\begin{array}{l}\text { DeLone dan } \\
\text { McLean (1992) }\end{array}$ \\
\hline & Kenyamanan Akses & $\mathrm{X} 1.6$ & $\begin{array}{l}\text { Mudah dalam mengakses Sistem Informasi } \\
\text { Akademik untuk mendapatkan informasi. }\end{array}$ & \multirow[t]{7}{*}{$\begin{array}{l}\text { Bailey dan } \\
\text { Pearson (1983) }\end{array}$} \\
\hline \multirow{6}{*}{$\begin{array}{l}\text { Kualitas } \\
\text { Informasi } \\
\text { (X2) }\end{array}$} & Akurasi & $\mathrm{X} 2.1$ & $\begin{array}{l}\text { Informasi pada Sistem Informasi Akademik } \\
\text { sangat akurat dan bebas dari kesalahan. }\end{array}$ & \\
\hline & Ketepatwaktuan & $\mathrm{X} 2.2$ & $\begin{array}{l}\text { Informasi pada Sistem Informasi Akademik } \\
\text { disajikan tepat waktu. Informasi yang diterima } \\
\text { pengguna tidak terlambat. }\end{array}$ & \\
\hline & Kekinian & $\mathrm{X} 2.3$ & $\begin{array}{l}\text { Sistem Informasi Akademik memberikan } \\
\text { informasi yang up to date. }\end{array}$ & \\
\hline & Kelengkapan & $\mathrm{X} 2.4$ & $\begin{array}{l}\text { Sistem Informasi Akademik memberikan } \\
\text { informasi yang bersifat lengkap }\end{array}$ & \\
\hline & Bentuk & $\mathrm{X} 2.5$ & $\begin{array}{l}\text { Informasi yang disaijkan Sistem Informasi } \\
\text { Akademik dapat dibaca denggan jelas dan baik } \\
\text { dalam format penulisannya. }\end{array}$ & \\
\hline & Relevan & $\mathrm{X} 2.6$ & $\begin{array}{l}\text { Sistem Informasi Akademik menampilkan } \\
\text { informasi yang dibutuhkan pengguna. }\end{array}$ & \\
\hline \multirow[t]{2}{*}{$\begin{array}{l}\text { Kualitas } \\
\text { Layanan (X3) }\end{array}$} & Kecepatan Respon & X3.1 & $\begin{array}{l}\text { Sistem Informasi Akademik memberikan } \\
\text { pelayanan kepada pengguna dengan cepat. }\end{array}$ & \multirow[t]{2}{*}{$\begin{array}{l}\text { DeLone dan } \\
\text { McLean (2003) }\end{array}$} \\
\hline & Jaminan & X3.2 & $\begin{array}{l}\text { Sistem Informasi Akademik memberikan } \\
\text { pelayanan yang didukung oleh teknisi } \\
\text { professional dalam menangani masalah yang } \\
\text { terjadi pada sistem. }\end{array}$ & \\
\hline \multicolumn{5}{|c|}{ Variabel Dependen } \\
\hline \multirow{3}{*}{$\begin{array}{l}\text { Kepuasan } \\
\text { Pengguna } \\
\text { (Y1) }\end{array}$} & $\begin{array}{l}\text { Kepuasan Terhadap } \\
\text { Informasi Pemakai }\end{array}$ & Y1.1 & $\begin{array}{l}\text { Kepuasan pengguna Sistem Informasi } \\
\text { Akademik dalam mendapatkan informasi. }\end{array}$ & $\begin{array}{l}\text { Boroudi, Olson } \\
\text { dan Ives (1985) }\end{array}$ \\
\hline & $\begin{array}{l}\text { Kepuasan Pengguna } \\
\text { Terhadap Interface }\end{array}$ & Y1.2 & $\begin{array}{l}\text { Kepuasan pengguna terhadap tampilan atau } \\
\text { interface Sistem Informasi Akademik yang } \\
\text { mencakup tata letak, format tulisan, fungsi } \\
\text { menu dan lain-lain. }\end{array}$ & $\begin{array}{l}\text { Taylor dan } \\
\text { Wang (1987) }\end{array}$ \\
\hline & Kepuasan Menyeluruh & Y1.3 & $\begin{array}{l}\text { Kepuasan pengguna dalam menggunakan } \\
\text { Sistem Informasi Akademik secara } \\
\text { keseluruhan. }\end{array}$ & $\begin{array}{l}\text { Ginzberg } \\
(1981)\end{array}$ \\
\hline
\end{tabular}

Sumber: Hasil Penelitian (2020)

Pada penelitian ini Kualitas Sistem (X1), Kualitas Informasi (X2), Kualitas Layanan (X3) dan Kepuasan Pengguna (Y1) adalah variabel-variabel yang digunakan sebagai hipotesis. 


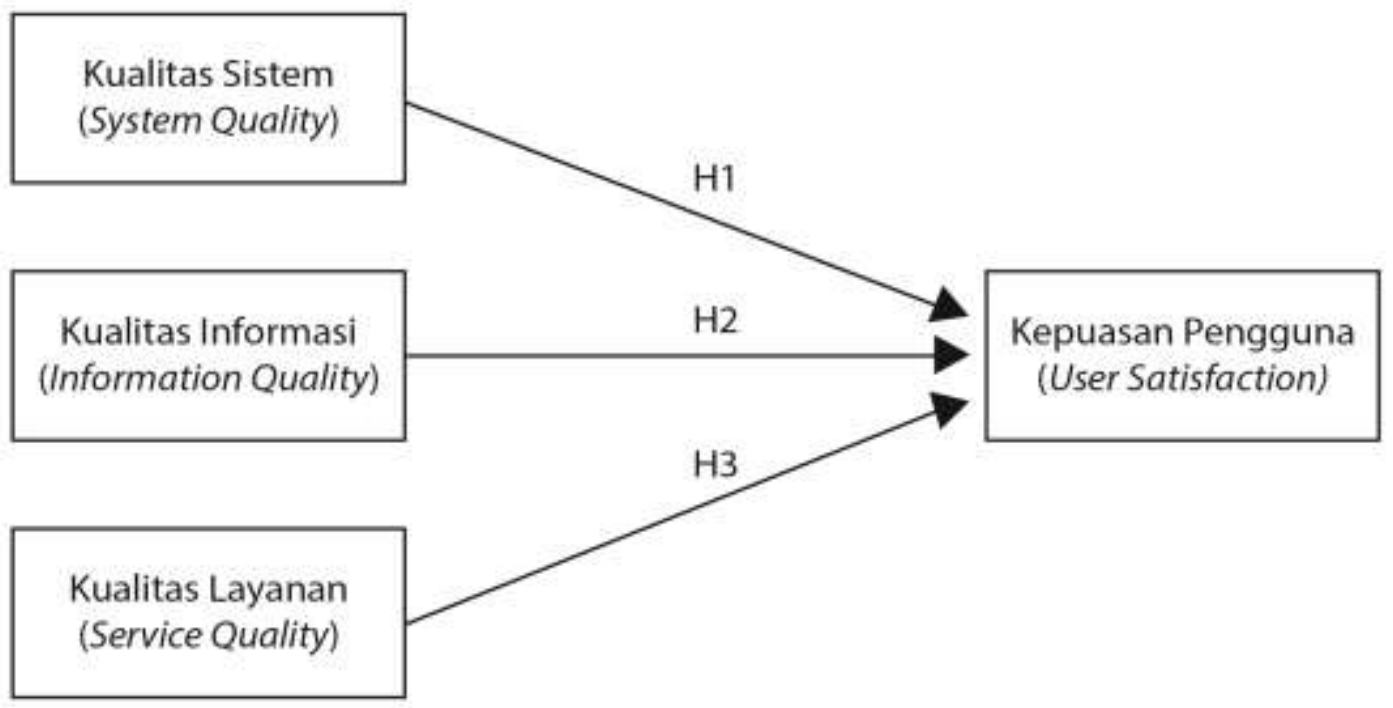

Sumber: Hasil Penelitian (2020)

Gambar 1. Hipotesis Penelitian

Adapun hipotesis yang terbentuk, dapat dilihat pada tabel 2 berikut:

Tabel 2. Hipotesis yang terbentuk

No Keterangan

1 Hipotesis pertama ( $\mathrm{H} 1)$ untuk mengetahui pengaruh Kualitas Sistem (System Quality) terhadap Kepuasan Pengguna (User Sastisfaction).

HO : Tidak ada pengaruh positif antara Kualitas Sistem (System Quality) dari Sistem Informasi Akademik dengan Kepuasan Pengguna (User Sastisfaction).

H1 : Ada pengaruh positif antara Kualitas Sistem (System Quality) dari Sistem Informasi Akademik dengan Kepuasan Pengguna (User Sastisfaction).

2 Hipotesis kedua $(\mathrm{H} 2)$ untuk mengetahui pengaruh Kualitas Informasi (Information Quality) terhadap kepuasan pengguna (User Sastisfaction).

HO :Tidak ada pengaruh positif antara Kualitas Informasi (Information Quality) dari Sistem Informasi Akademik dengan Kepuasan Pengguna (User Sastisfaction).

H1 :Ada pengaruh positif antara Kualitas Informasi (Information Quality) dari Sistem Informasi Akademik dengan Kepuasan Pengguna (User Sastisfaction).

3 Hipotesis ketiga $(\mathrm{H} 3)$ untuk mengetahui pengaruh Kualitas Layanan (Service Quality) terhadap Kepuasan Pengguna (User Sastisfaction).

H0:Tidak ada pengaruh positif antara Kualitas Layanan (Service Quality) dari Sistem Informasi Akademik dengan Kepuasan Pengguna (User Sastisfaction).

H1:Ada pengaruh positif antara Kualitas Layanan (Service Quality) dari Sistem Informasi Akademik dengan Kepuasan Pengguna (User Sastisfaction).

Sumber: Hasil Penelitian (2020)

\section{Metode Partial Least Square (PLS)}

Partial Least Square adalah teknik statistika multivariat yang melakukan perbandingan antara variabel dependen berganda dan variabel independen jamak. PLS adalah salah satu metode statistika SEM berbasis varian yang didesain untuk menyelesaikan regresi berganda ketika terjadi permasalahan spesifik pada data, seperti ukuran sampel penelitian kecil, adanya data yang hilang (missing values) dan multikolinearitas [2].

Analisis PLS-SEM biasanya terdiri dari dua sub model yaitu model pengukuran (measurement model) atau sering disebut outer model dan model struktural (structural model) atau sering disebut inner model. Model pengukuran menunjukan bagaimana variabel manifest atau observed variabel merepresentasikan variabel laten untuk diukur. Sedangkan model struktural menunjukan kekuatan estimasi antar variabel laten atau konstruk [5].

Model Pengukuran (Outer Model) diukur dengan 3 kriterian yaitu 1). Validitas Konvergen dilihat dari nilai Average Variance Extracted (AVE) $>0,5$. Rule of thumb yang digunakan untuk validitas konvergen adalah Outer Loading $>0,7$ dan Average Variance Extracted (AVE) $>0,5$ [2], 2). Validitas Diskriminan dilihat dari nilai Cross Loading $>0,7$ atau metode lain dengan 
Fornell-Larcker Criterion [2], 3). Konstruk Reliabilitas diukur dengan nilai Composite Reliability dan Cronbach's Alpha masing-masing > 0,7 meskipun nilai 0,6 masih dapat diterima [2].

Model Struktural (Inner Model) dengan 3 kriterian yaitu 1). Koefisiensi Determinasi $\mathrm{R}^{2}$ yaitu $0.75,0.50,0.25$ disimpulkan kuat, moderate dan lemah [5], 2). Koefisiensi Jalur jika nilai > 0,1 maka menunjukkan hubungan positif dan dapat dinyatakan memiliki pengaruh yang kuat dalam model, sedangkan jika nilai $<0,1$ maka menunjukkan hubungan negatif dan dinyatakan tidak memiliki pengaruh yang kuat dalam model, 3). T-Statistic dengan Bootstraping yaitu apabila nilai $T$-Statistic $\geq 1,96$ mana menunjukan adanya hubungan yang signifikan antara variabel atau sebaliknya jika nilai $T$-Statistic $<1,96$ maka tidak ada hubungan yang signifikan.

\section{Metode Kuesioner}

Penelitian ini menggunakan metode penelitian kuantitatif, dimana peneliti membuat daftar pertanyaan dalam bentuk kuesioner yang berisi 23 pertanyaan. Adapun skala untuk mengukur jawaban setiap item pertanyaan dengan menggunakan Skala Likert 1-5. Skala Likert digunakan untuk mengukur sikap, pendapat, dan persepsi seseorang atau kelompok tentang fenomena sosial [6].

\section{Kerangka Pemikiran}

Peneliti menuangkan kedalam kerangka pemikiran dalam menentukan faktor-faktor pada Sistem Informasi Akademik yang secara praktis menggambarkan tahapan-tahapan penelitian.

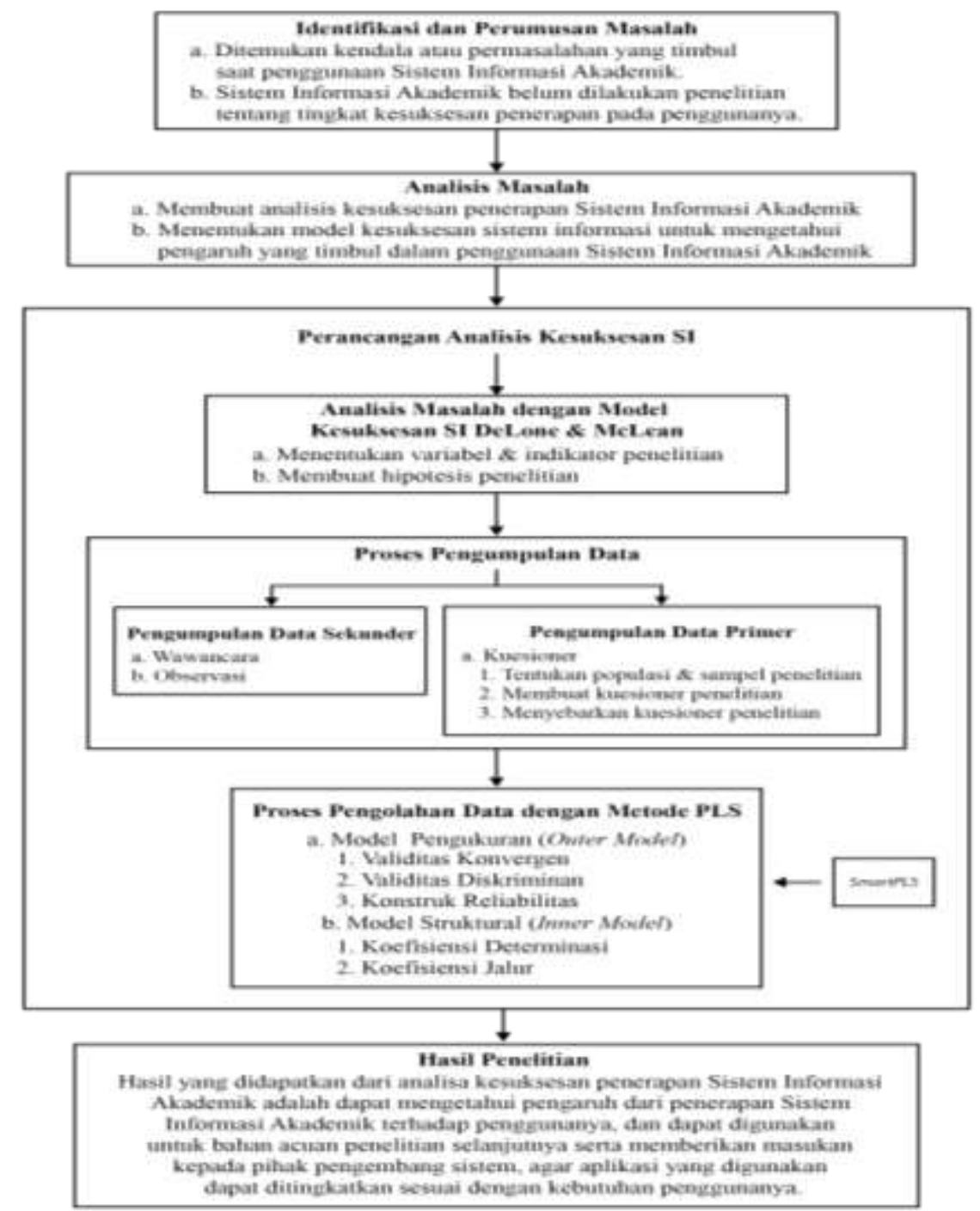

Sumber: Hasil Penelitian (2020)

Gambar 2. Kerangka Pemikiran 


\section{Hasil dan Pembahasan}

Pada bagian ini akan menjelaskan hasil dan pembahasan mengenai Model Kesuksesan Sistem Informasi Delone Dan Mclean Terhadap Sistem Informasi Akademik di Universitas Bina Insani.

\section{Skenario Pengumpulan Data}

Populasi penelitian adalah mahasiswa dan dosen fakultas informatika serta bagian akademik dan bagian keuangan dengan jumlah sebanyak 529. Pengambilan sampel menggunakan teknik Disproportionate Stratified Random Sampling dengan rumus Slovin dengan tingkat signifikansi $10 \%$. Sehingga jumlah sampel yang digunakan pada penelitian ini sebanyak 92 sampel penelitian yang dijadikan sebagai responden.

Penyebaran kuesioner dilakukan secara online menggunakan kuesioner online yaitu google form. Hal ini dilakukan karena kondisi pandemi yang tidak memungkinkan untuk menyebarkan secara langsung. Penyebaran kuesioner online dimulai tanggal 20 mei 2020 sampai dengan 25 mei 2020 secara personal melalui media sosial. Adapun kuesioner yang disebarkan sebanyak 105 kuesioner. Terdapat 13 kueioner yang tidak kembali dan 92 yang kembali.

\section{Hasil Pengolahan Data}

Pengolahan data menggunakan metode Partial Least Square (PLS) dengan alat bantu hitung SmartPLS. Terdapat 2 tahap analisis yaitu Model Pengukuran (Outer Model) dan Model Struktural (Inner Model).

\section{Model Pengukuran (Outer Model)}

Model Pengukuran (Outer Model) adalah mengukur korelasi antara indikator dengan konstruk atau variabel laten. Model Pengukuran ini digunakan untuk menguji validitas konstruk dan reliabilitas instrumen. Pengujian validitas dan reliabilitas suatu model diukur dari 3 kriteria yaitu Validitas Konvergen (Convergent Validity), Validitas Diskriminan (Dicriminant Validity), dan Konstruk Reliabilitas (Construct Reliability).

\section{Uji Validitas Konvergen}

Berikut hasil perhitungan diperoleh dari pengujian Validitas Konvergen berdasarkan nilai Loading Factor per indikator dan nilai Average Covariance Extracted (AVE) adalah sebagai berikut:

Tabel 3. Nilai Loading Factor

\begin{tabular}{|c|c|c|c|c|}
\hline $\begin{array}{l}\text { Variabel } \\
\text { Indikator }\end{array}$ & $\begin{array}{c}\text { Kualitas Sistem } \\
\text { (X1) }\end{array}$ & $\begin{array}{c}\text { Kualitas Informasi } \\
\text { (X2) }\end{array}$ & $\begin{array}{c}\text { Kualitas Layanan } \\
\text { (X3) }\end{array}$ & $\begin{array}{c}\text { Kepuasan Pengguna } \\
\text { (Y1) }\end{array}$ \\
\hline X1.1 & 0,404 & & & \\
\hline $\mathrm{X} 1.2$ & 0,759 & & & \\
\hline $\mathrm{X} 1.3$ & 0,713 & & & \\
\hline X1.4 & 0,713 & & & \\
\hline $\mathrm{X} 1.5$ & 0,694 & & & \\
\hline X1.6 & 0,770 & & & \\
\hline $\mathrm{X} 1.7$ & 0,667 & & & \\
\hline $\mathrm{X} 1.8$ & 0,529 & & & \\
\hline X1.9 & 0,262 & & & \\
\hline $\mathrm{X} 1.10$ & 0,546 & & & \\
\hline X1.11 & 0,456 & & & \\
\hline X2.1 & & 0,683 & & \\
\hline $\mathrm{X} 2.2$ & & 0,697 & & \\
\hline X2.3 & & 0,739 & & \\
\hline X2.4 & & 0,853 & & \\
\hline $\mathrm{X} 2.5$ & & 0,675 & & \\
\hline $\mathrm{X} 2.6$ & & 0,798 & & \\
\hline X3.1 & & & 0,840 & \\
\hline $\mathrm{X} 3.2$ & & & 0,937 & \\
\hline X33 & & & 0,914 & \\
\hline Y1.1 & & & & 0,857 \\
\hline Y1.2 & & & & 0,827 \\
\hline
\end{tabular}


Y1.3

Sumber: Hasil Penelitian (2020)

Tabel 4. Nilai Average Variance Extracted (AVE)

\begin{tabular}{cc}
\hline Variabel & Average Variance Extracted (AVE) \\
\hline $\mathbf{X 1}$ & 0.370 \\
\hline $\mathbf{X} 2$ & 0.553 \\
\hline $\mathbf{X 3}$ & 0.806 \\
\hline Y1 & 0.731
\end{tabular}

Sumber: Hasil Penelitian (2020)

Berdasarkan hasil perhitungan nilai Loading Factor dan nilai Average Covariance Extracted (AVE) menunjukkan tingkat validitas atas kuesioner yang digunakan belum menunjukkan tingkat validitas yang baik. Nilai Outer Loading yang dihasilkan pada Tabel IV.8 yang bertanda merah masih dibawah 0,6 yaitu indikator X1.1, X1.8, X1.9, X.10, dan X1.11 untuk variabel Kualitas Sistem. Sedangkan untuk nilai Average Covariance Extracted (AVE) untuk variabel X1 pada Tabel IV.9 belum mencapai batas yaitu $>0,5$.

Oleh karena itu peneliti melakukan modifikasi terhadap model penelitian yaitu dengan menghapus indikator yang nilainya dibawah 0,6 karena pada penelitian ini batas nilai yang digunakan yaitu Outer Loading > 0,6. Indikator yang telah dihapus tidak akan dalam pembahasan selanjutnya indikator tersebut tidak akan dibahas.

Peneliti melakukan pengujian ulang dan menghapus indikator sesuai dengan pertimbangan diatas. Berikut hasil perhitungan diperoleh Validitas Konvergen berdasarkan nilai Loading Factor dan nilai Average Covariance Extracted (AVE) setelah penghapusan indikator adalah sebagai berikut:

Tabel 5. Nilai Loading Factor setelah penghapusan indikator

\begin{tabular}{|c|c|c|c|c|}
\hline $\begin{array}{l}\text { Variabel } \\
\text { Indikator }\end{array}$ & $\begin{array}{c}\text { Kualitas Sistem } \\
\text { (X1) }\end{array}$ & $\begin{array}{c}\text { Kualitas Informasi } \\
\text { (X2) }\end{array}$ & $\begin{array}{c}\text { Kualitas Layanan } \\
\text { (X3) }\end{array}$ & $\begin{array}{c}\text { Kepuasan Pengguna } \\
\text { (Y1) }\end{array}$ \\
\hline $\mathrm{X} 1.2$ & 0,789 & & & \\
\hline $\mathrm{X} 1.3$ & 0,775 & & & \\
\hline X1.4 & 0,729 & & & \\
\hline X1.5 & 0,720 & & & \\
\hline X1.6 & 0,793 & & & \\
\hline $\mathrm{X} 1.7$ & 0,636 & & & \\
\hline X2.1 & & 0,682 & & \\
\hline $\mathrm{X} 2.2$ & & 0,697 & & \\
\hline $\mathrm{X} 2.3$ & & 0,739 & & \\
\hline $\mathrm{X} 2.4$ & & 0,853 & & \\
\hline $\mathrm{X} 2.5$ & & 0,675 & & \\
\hline X2.6 & & 0,798 & & \\
\hline X3.1 & & & 0,840 & \\
\hline X3.2 & & & 0,937 & \\
\hline X33 & & & 0,914 & \\
\hline Y1.1 & & & & 0,856 \\
\hline Y1.2 & & & & 0,830 \\
\hline Y1.3 & & & & 0,878 \\
\hline
\end{tabular}

Tabel 6. Nilai Average Variance Extracted (AVE) setelah penghapusan indikator Variabel

\begin{tabular}{|c|c|}
\hline & (1) \\
\hline $\mathbf{X 1}$ & 0.55 \\
\hline $\mathrm{X} 2$ & 0.55 \\
\hline $\mathbf{X} 3$ & 0.80 \\
\hline Y1 & 0.73 \\
\hline
\end{tabular}

Setelah dilakukan penghapusan indikator yang nilai Outer Loading $>0,6$ maka sudah dapat dipastikan indikator sudah valid. Selanjutnya dapat melanjutkan ke pengujian Validitas Diskriminan. 


\section{Uji Validitas Diskriminan}

Berikut hasil perhitungan diperoleh dari pengujian Validitas Konvergen berdasarkan nilai Cross Loading dan nilai Fornell Larcker Criterion adalah sebagai berikut:

Tabel 7. Nilai Cross Loading

\begin{tabular}{|c|c|c|c|c|}
\hline $\begin{array}{l}\text { Variabel } \\
\text { Indikator }\end{array}$ & $\begin{array}{c}\text { Kualitas Sistem } \\
\text { (X1) }\end{array}$ & $\begin{array}{c}\text { Kualitas Informasi } \\
\text { (X2) }\end{array}$ & $\begin{array}{c}\text { Kualitas Layanan } \\
\text { (X3) }\end{array}$ & $\begin{array}{c}\text { Kepuasan Pengguna } \\
\text { (Y1) }\end{array}$ \\
\hline X1.3 & 0,775 & 0,314 & 0,429 & 0,542 \\
\hline X1.5 & 0,720 & 0,512 & 0,450 & 0,583 \\
\hline X1.6 & 0,793 & 0,467 & 0,418 & 0,600 \\
\hline X1.7 & 0,636 & 0,354 & 0,331 & 0,525 \\
\hline X2.2 & 0,265 & 0,697 & 0,138 & 0,378 \\
\hline X2.3 & 0,375 & 0,739 & 0,438 & 0,457 \\
\hline X2.4 & 0,456 & 0,853 & 0,331 & 0,577 \\
\hline X2.5 & 0,583 & 0,675 & 0,400 & 0,563 \\
\hline X2.6 & 0,473 & 0,798 & 0,284 & 0,508 \\
\hline X3.1 & 0,456 & 0,406 & 0,839 & 0,429 \\
\hline Y1.2 & 0,684 & 0,498 & 0,433 & 0,832 \\
\hline Y1.3 & 0,718 & 0,551 & 0,559 & 0,877 \\
\hline
\end{tabular}

Sumber: Hasil Penelitian (2020)

Dapat dilihat bahwa nilai Cross Loading dari variabel X1 (Kualitas Sistem) jika dibandingkan dengan variabel lain nilainya lebih besar. Variabel X2 (Kualitas Informasi) jika dibandingkan dengan variabel lain nilainya lebih besar. Variabel X3 (Kualitas Layanan) jika dibandingkan dengan variabel lain nilainya lebih besar. Variabel Y1 (Kepuasan Pengguna) jika dibandingkan dengan variabel lain nilainya lebih besar. Hal ini berarti uji Validitas Diskriminan berdasarkan nilai Cross Loading dapat dikatakan valid. Selanjutnya untuk dapat memperkuat pernyataan tersebut dapat dilihat dari nilai Fornell Larcker Criterion pada Tabel. 4.

Tabel 8. Nilai Fornell Larcker Criterion

\begin{tabular}{ccccc}
\hline Variabel & $\begin{array}{c}\text { Kualitas Sistem } \\
\text { (X1) }\end{array}$ & $\begin{array}{c}\text { Kualitas Informasi } \\
(\mathbf{X})\end{array}$ & $\begin{array}{c}\text { Kualitas Layanan } \\
(\mathbf{X} 3)\end{array}$ & $\begin{array}{c}\text { Kepuasan Pengguna } \\
\text { (Y1) }\end{array}$ \\
\hline X1 & 0,744 & & & \\
\hline $\mathbf{X 2}$ & 0,567 & 0,744 & & \\
\hline $\mathbf{X 3}$ & 0,550 & 0,413 & 0,898 & 0,855 \\
\hline Y1 & 0,774 & 0,653 & 0,569 & \\
\hline
\end{tabular}

Sumber: Hasil Penelitian (2020)

Perbandingan nilai Fornell Larcker Criterion yaitu nilai variabel X1 jika dibandingkan dengan variabel lain masih lebih kecil yaitu $X 1 \quad(0,744)$ dibandingkan dengan $Y 1(0,774)$ sedangkan untuk variabel $\mathrm{X} 2, \mathrm{X} 3$ dan $\mathrm{Y} 1$ jika dibandingkan dengan variabel lainnya memiliki nilai Fornell Larcker Criterion lebih besar. Oleh karena itu, dilakukan penghapusan indikator pada Outer Loading hal ini disebabkan karena nilai korelasi yang dihasilkan pada Factor Loading mengakibatkan terjadinya lack pada Fornell Larcker Criterion.

Adapun indikator yang dihapus yaitu indikator dari variabel $\mathrm{X} 1$ dan variabel $\mathrm{Y} 1$ yang memiliki nilai paling kecil. Berikut perhitungan dari nilai Outer Loading yang dihasilkan setelah penghapusan indikator:

Tabel 9. Nilai Loading Factor

\begin{tabular}{ccccc}
\hline $\begin{array}{c}\text { Variabel } \\
\text { Indikator }\end{array}$ & $\begin{array}{c}\text { Kualitas Sistem } \\
(\mathbf{X} 1)\end{array}$ & $\begin{array}{c}\text { Kualitas Informasi } \\
(\mathbf{X} 2)\end{array}$ & $\begin{array}{c}\text { Kualitas Layanan } \\
(\mathbf{X})\end{array}$ & $\begin{array}{c}\text { Kepuasan Pengguna } \\
(\mathbf{Y} 1)\end{array}$ \\
\hline $\mathbf{X} 1.2$ & 0,789 & & \\
\hline $\mathbf{X} 1.3$ & 0,775 & & \\
\hline $\mathbf{X} 1.4$ & 0,729 & & \\
\hline $\mathbf{X} 1.5$ & 0,720 & \\
\hline $\mathbf{X} 1.6$ & 0,793 & \\
\hline $\mathbf{X} 1.7$ & 0,636 & \\
\hline $\mathbf{X} 2.1$ & & 0,682 \\
\hline
\end{tabular}




\begin{tabular}{|c|c|c|c|c|}
\hline $\begin{array}{l}\text { Variabel } \\
\text { Indikator }\end{array}$ & $\begin{array}{l}\text { Kualitas Sistem } \\
\text { (X1) }\end{array}$ & $\begin{array}{c}\text { Kualitas Informasi } \\
\text { (X2) }\end{array}$ & $\begin{array}{c}\text { Kualitas Layanan } \\
\text { (X3) }\end{array}$ & $\begin{array}{c}\text { Kepuasan Pengguna } \\
\text { (Y1) }\end{array}$ \\
\hline X2.2 & & 0,697 & & \\
\hline $\mathrm{X} 2.3$ & & 0,739 & & \\
\hline $\mathrm{X} 2.4$ & & 0,853 & & \\
\hline X2.5 & & 0,675 & & \\
\hline X2.6 & & 0,798 & & \\
\hline X3.1 & & & 0,840 & \\
\hline X3.2 & & & 0,937 & \\
\hline X33 & & & 0,914 & \\
\hline Y1.1 & & & & 0,856 \\
\hline Y1.2 & & & & 0,830 \\
\hline Y1.3 & & & & 0,878 \\
\hline
\end{tabular}

Adapun indikator yang dihapus yaitu indikator X1.7 dari variabel X1 (Kualitas Sistem) dengan nilai 0,636 dan Y1.2 dari variabel Y1 (Kepuasan Pengguna) dengan nilai 0,830. Selanjutnya dipastikan kembali nilai Fornell Larcker Criterion pada variabel X1 lebih besar jika dibandingkan dengan variabel Y1 adalah lebih besar. Berikut hasil dari nilai Fornell Larcker Criterion:

Tabel 10. Nilai Fornell Larcker Criterion

\begin{tabular}{ccccc}
\hline Variabel & $\begin{array}{c}\text { Kualitas Sistem } \\
\text { (X1) }\end{array}$ & $\begin{array}{c}\text { Kualitas Informasi } \\
\text { (X2) }\end{array}$ & $\begin{array}{c}\text { Kualitas Layanan } \\
\text { (X3) }\end{array}$ & $\begin{array}{c}\text { Kepuasan Pengguna } \\
\text { (Y1) }\end{array}$ \\
\hline X1 & 0,776 & & & \\
\hline X2 & 0,553 & 0,745 & & \\
\hline X3 & 0,540 & 0,407 & 0,898 & 0,907 \\
\hline Y1 & 0,705 & 0,645 & 0,565 & \\
\hline
\end{tabular}

Sumber: Hasil Penelitian (2020)

Adapun nilai Fornell Larcker Criterion yang ditunjukkan pada Tabel.6 memiliki nilai Validitas Diskriminan yang baik, yaitu akar AVE setiap konstruk lebih besar daripada nilai korelasi antara satu variabel dengan variabel lainnya.

\section{Uji Konstruk Reliabilitas}

Berikut hasil perhitungan diperoleh dari pengujian Konstruk Reliabilitas berdasarkan nilai Cronbach's Alpha dan nilai Composite Reliability adalah sebagai berikut:

Tabel 11. Nilai Cronbach's Alpha dan Composite Reliability

\begin{tabular}{ccc}
\hline Variabel & Cronbach's Alpha & Composite Reliability \\
\hline X1 & 0.835 & 0.883 \\
\hline X2 & 0.839 & 0.882 \\
X3 & 0.880 & 0.926 \\
\hline Y1 & 0.784 & 0.902
\end{tabular}

Sumber: Hasil Penelitian (2020)

Berdasarkan hasil tersebut, diketahui bahwa nilai Cronbach's Alpha dan Composite Reliability dari semua variabel sudah memenuhi syarat model yang baik yaitu dihasilkan variabel masing-masing $>0,7$. Hal ini menunjukkan bahwa butir-butir pertanyaan dalam kuesioner dapat dikatakan reliabel atau terpercaya sebagai data dalam penelitian. Berdasarkan tahap yang telah dilakukan sebelumnya, dapat diketahui model dalam penelitian ini telah memenuhi persyaratan model yang baik secara statistik sehingga dapat disimpulkan dari hasil analisis Model Pengukuran (Outer Model) dapat dilajutkan ke tahap pengujian Model Struktur (Inner Model).

\section{Model Struktural (Inner Model)}

Model Struktural (Inner Model) menggambarkan hubungan antara variabel laten dalam model. Pada tahap analisis model struktural dilakukan tahap pengujian, yang terdiri dari pengujian Koefisiensi Determinasi $\left(R^{2}\right)$ (Coefficient of Determination), pengujian Koefisensi Jalur (Path Coefficient) dan T-Statistik menggunakan metode Bootstraping.

\section{Uji Koefisiensi Determinasi $\left(\mathbf{R}^{2}\right)$}

Berikut hasil perhitungan diperoleh dari pengujian Koefisensi Determinasi $\left(R^{2}\right)$ berdasarkan nilai $R$-square adalah sebagai berikut: 
Tabel 12. Nilai Koefisiensi Determinasi $\left(\mathrm{R}^{2}\right)$

\begin{tabular}{cc}
\hline Variabel & Koefisiensi Determinasi $\left(\mathbf{R}^{2}\right)$ \\
\hline Y1 & 0,620
\end{tabular}

Berdasarkan hasil tersebut, nilai koefisiensi determinasi $\left(R^{2}\right)$ dari kepuasan pengguna bernilai 0,620 menunjukkan variabel Kualitas Sistem, Kualitas Informasi Dan Kualitas Layanan dapat mempengaruhi variabel Kepuasan Pengguna sebesar 62\%, sedangkan 38\% dijelaskan oleh variabel lain diluar model yang diteliti. Dengan demikian model tersebut tergolong kedalam model yang moderate.

\section{Uji Koefisiensi Jalur}

Berikut hasil perhitungan diperoleh dari pengujian Koefisiensi Jalur yang dapat dilihat pada Tabel 9.

Tabel 13. Nilai Koefisiensi Jalur

\begin{tabular}{cccc}
\hline Hipotesis & \multicolumn{2}{c}{ Jalur } & \multicolumn{2}{c}{ Path Coefficients } \\
\cline { 2 - 4 } & Dari & Ke & 0,407 \\
\hline H1 & $\mathrm{X} 1$ & $\mathrm{Y} 1$ & 0,336 \\
\hline H2 & $\mathrm{X} 2$ & $\mathrm{Y} 1$ & 0,206 \\
\hline
\end{tabular}

Sumber: Hasil Penelitian (2020)

Berdasarkan hasil tersebut, terdapat 3 jalur yang ada pada model penelitian, semua jalur menunjukan pengaruh hubungan positif karena nilai Koefisiensi Jalur yang dihasilkan berada pada rentang nilai 0 - 1 yang apabila dijabarkan yaitu nilai Koefisiensi Jalur $\mathrm{X} 1 \rightarrow \mathrm{Y} 1$ memiliki nilai sebesar $0,407, \mathrm{X} 2 \rightarrow \mathrm{Y} 1$ memiliki nilai Koefisiensi Jalur yaitu 0,336 dan $\mathrm{X} 3 \rightarrow \mathrm{Y} 1$ memiliki nilai koefisiensi jalur yaitu 0,206.

\section{Uji T-Statistic}

Berikut hasil perhitungan diperoleh dari pengujian T-Statistic menggunakan metode Bootsraping. Pengujian ini dilakukan untuk mengetahui adanya hubungan yang signifikan antara variabel.

\begin{tabular}{ccc}
\multicolumn{3}{c}{ Tabel 14. Nilai T-Statistics } \\
\hline Hubungan Variabel & T-Statictics \\
\hline $\mathbf{X} 1 \rightarrow$ Y1 & 4.699 \\
\hline $\mathbf{X} \rightarrow$ Y1 & 2.782 \\
\hline $\mathbf{X} 3 \rightarrow$ Y1 & 1.898
\end{tabular}

Sumber: Hasil Penelitian (2020)

Berdasarkan hasil tersebut, dapat disimpulkan bahwa terdapat 3 hubungan variabel yang mana hubungan $\mathrm{X} 1 \rightarrow \mathrm{Y} 1$ dan $\mathrm{X} 2 \rightarrow \mathrm{Y} 1$ memiliki hubungan yang signifikan karena nilai $T$ Statistic $>1,96$ sedangkan untuk hubungan $\mathrm{X} 3 \rightarrow \mathrm{Y} 1$ memiliki hubungan yang tidak signifikan karena nilai dari $T$-Statistic pada hubungan tersebut $<1,96$.

\section{Kesimpulan}

Berdasarkan hasil analisis dan pengujian-pengujian yang telah dilakukan, maka dapat disimpulkan bahwa sebagai berikut: 1). Kualitas Sistem (System Quality) terbukti memberikan pengaruh positif dan signifikan terhadap Kepuasan Pengguna (User Satisfaction). Hal ini dibuktikan dengan nilai Koefisiensi jalur sebesar 0,407 dan nilai T-Statistic sebesar 4,699. Hal ini dapat menjawab atas hipotesis dalam penelitian yaitu bahwa hipotesis $\mathrm{H} 0$ ditolak dan $\mathrm{H} 1$ diterima, 2). Kualitas Informasi (Information Quality) terbukti memberikan pengaruh positif dan signifikan terhadap Kepuasan Pengguna (User Satisfaction). Hal ini dibuktikan dengan nilai Koefisiensi jalur sebesar 0,336 dan nilai T-Statistic sebesar 2,782. Hal ini dapat menjawab atas hipotesis dalam penelitian yaitu bahwa hipotesis $\mathrm{H} 0$ ditolak dan $\mathrm{H} 1$ diterima, 3). Kualitas Layanan (Service Quality) terbukti memberikan pengaruh positif tetapi tidak signifikan terhadap Kepuasan Pengguna (User Satisfaction). Hal ini dibuktikan dengan nilai Koefisiensi jalur sebesar 0,206 dan nilai $T$-Statistic sebesar 1,898. Hal ini dapat menjawab atas hipotesis dalam penelitian yaitu bahwa hipotesis $\mathrm{H} 0$ ditolak dan $\mathrm{H} 1$ diterima. 


\section{Referensi}

[1] R. Jumardi, E. Nugroho, And I. Hidayah, Analisis Kesuksesan Implementasi Sistem Informasi Skripsi Pada Program Studi Teknik Informatika Universitas Pembangunan Nasional ' Veteran' Yogyakarta, Seminar Nasional Aplikasi Teknologi Informasi, 2015.

[2] W. Abdillah, Metode Penelitian Terpadu Sistem Informasi - Pemodelan Teoretis, Pengukuran, Dan Pengujian Statistis, 1st Ed. Yogyakarta: Andi, 2018.

[3] M. Qadri, Pengaruh Kualitas Sistem Informasi Akademik (Berbasis Web) Dan Kinerja Unit Layanan Terhadap Kepuasan Mahasiswa Di Perguruan Tinggi Swasta, 1st Ed. Yogyakarta: Gawe Buku, 2017.

[4] M. Rakhmadian, S. Hidayatullah, And H. Respati, "Analisis Kualitas Sistem Dan Kualitas Informasi Terhadap Kepuasan Pemakai Sistem Informasi Akademik Dosen," Seminar Nasional Sistem Informasi, 2017.

[5] I. Ghozali And H. Latan, Partial Least Square Konsep, Teknik Dan Aplikasi Menggunakan Program Smartpls 3.0 Untuk Penelitian Empiris, 2nd Ed. Semarang: Badan Penerbit Universitas Diponegoro, 2015.

[6] S. Sugiyono, Metode Penelitian Kuantitatif, Kualitatif, Dan Kombinasi (Mixed Methods), 9th Ed. Bandung: Alfabeta CV, 2017. 